\title{
Introdução à História do Direito Japonês*
}

\author{
Yuko Nishitani \\ Professora de Diretto Internacional Privado da Universidade Tohoku, \\ SENDAI, JAPÃO

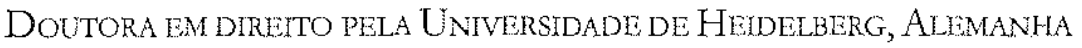 \\ Mestrado em Direito pela Universiadde de Kyoto, Jarão
}

\begin{abstract}
Sumário: 1. A história do direito japonês. - a) O período antigo - b) O periodo feudal. - c) A recepção do direito ocidental. - d) Depois da Segunda Guerra Mundial. - 2. As características do ordenamento juridico japonêes.
\end{abstract}

\section{A história do direito japonês}

\section{a) $\mathrm{O}$ período antigo}

Conhecemos a situação política do Japão do século I ao III graças a algumas documentações encontradas na China, onde os japoneses, considerando-se a superioridade política e econômica da China, enviavam regularmente as delegações com homenagens/ ofertas ao imperador escravos, arroz e tecidos. Os documentos japoneses autênticos referem que, não muito depois do século IV, os reis (em seguida chamados "tennô" = imperadores) começarão a unificar e a dominar muitas partes do Japão, que antes eram/estavam sob a hegemonia dos clãs poderosos. Esses reis justificavam o seu poder apoiando-se no sbintoismo, isto é, na religião japonesa, na qual o rei vem considerado como um dos deí e o filho da deusa do sol Amaterasu.

- Esse artigo basein-se no seminário proferido na Università Statale di Milano em 06 de março de 2000, durante a minha permanência na Itália. Queria agradecer a professora Gigliola di Renzo Villata e o professor Antonio Padoa Schioppa por terem me dado a oportunidade de falar sobre a histónia do direito japonês no âmbito dos cursos por eles mantidos e por terem otganizado a publicaçāo na Itália.

1 Tradução livre autorizada de Maitê Schmidt (Grupo de Pesquisa CNpQ "Mercosul e Direito do consumidor"/UFRGS, boisista Propesq/UFRGS), ptimeira revisão de Luciana Quinto (Grupo de Pesquisa CNPq "Mercosul e Direito do consumidor"/UFRGS,), revisão final de Profa. Dra. Claudia Lima Marques, UFRGS. 
A forma do Estado foi completada no século VII (principalmente após a revolução de taika em 645) tomando como base a instituição chinesa. $\mathrm{Na}$ China, onde florescia a alta cultura da dinas tia de Tang (618-), a codificação acontece sob a influência do confucionismo e dos legalistas: em particular vêm redigir o código administrativo (ling) e o código penal (iii), junto com o agrupamento dos decretos provisórios $(g e)$ e das normas relativas à aplicação dos códigos. $O$ código penal $\left(1^{a}\right.$ edição em $624,2^{a}$ edição em 651$)$, para excluir a possibilidade de uma repressão penal arbitrária, continha um elenco de 445 figuras de crimes e das penas correspondentes; foi prevista também a diminuição da pena em razão do status social e do sexo do réu, da modalidade de execução do crime, dos motivos do réu, etc. ${ }^{2}$ Esse código penal foi tão avançado a ponto de não ser completamente inferior à Constitutio Criminalis Caralina de $1532^{3}$, promulgada cerca de novecentos anos depois ${ }^{4}$. Com base nesses códigos chineses, o imperador japonês promulgou o código penal (ritsu) e o código administrativo $(r y o)$ em diversas edições ${ }^{5}$. O código penal baseou-se quase textualmente na lei chinesa, enquanto o código administrativo, que regulava a ordem dos funcionários e dos monges, o pagamentos dos impostos, o sistema do exército, etc. refletia a tradição japonesa. Os especialistas, com um amplo conhecimento do sistema ritsury $\hat{o}$, eram formados numa escola especial. Para unificar as diversas interpretações entre os juristas foram redigidos os comentários, com centenas de volumes já na metade do século IX ${ }^{6}$.

É de se notar que o problema típico derivado da recepção de um ordenamento jurídico estrangeiro, isto é, a contradição entre o direito recepcionado e o direito tradicional, já se mostrava nesse periodo. Por exemplo, ao invés da linha genealógica masculina utilizada na China, no Japão dominava, naquela época, a linha feminina; portanto, presume-se que, em contraste com o texto da lei, o divórcio viesse executado, em muitos casos, segundo os costumes japoneses através do "repúdio do marido" e não segundo o dado normativo escrito, isto é, através do repúdio da esposa. Pode-se, assim, observar como nesse sentido prevaleceram os costumes japoneses sobre a norma escrita ${ }^{7}$. Eunbora o ritsuryô tivesse formalmente ficado em vigor até a metade do século XIX, perdeu pouco a pouco a sua real eficácia ${ }^{8}$.

${ }^{2}$ A. GAMBARO - R. SACCO, sisteni giunidic comparat, in Trattato di dinto comparato diretto (direto?) da R, SACCO, Torino 1996, p. 511. Por exemplo, o crime de percosse (golpes?) e lesões foi subdividido em quatro categonas segundo os meios (com a mão ou o pé, com a água fervente ou o fogo, com a espada ou a faca, com um outro objeto) e en outras categonas segundo os resultados (a ferida e o puxâo dos cabelos, a hemorcagia nos olhos e nas orelhas, o sangramento da boca, a perda dos dentes, etc). ÔTAKL - MAKI, Nitom bóserishi, Tokyo 1975 , pa $70 \mathrm{ss}$

${ }^{3}$ Veja A. CAVANNA, Storia del dirito moderno in Etropa, Milano 1982, p. 463.

${ }^{4}$ OTAKE - MAKI, op. ai. (1), pp. 22 ss. No inicio o procedimento penal deveria instaumr-se sempre com uma denúncia dos funcionários ou dos pariculares que arriscavam, por sua vez, de serem acusados de difamaçäo. O funcionário chamado a julgar a causa devia recolher as provas segundo o princípio do livre convencimento e, se as provas nầo eram suficientes, colocava o acusado na tornara (paridade das partes). Se o acusado não confessava, era torturado o acusador para verificar a inexistência da difamação. A apelação era prevista junto ao (presso) o tribunal colegial de dajotsan. Porém, no curso do tempo, o prinćpio da deníncia foi substimido por açuele da inquisição e a apelação foi abolida para simplificar o processo. OTAKE - MAKI, op. ait. (1), pp. 90 ss.

${ }^{5} \mathrm{O}$ taibó nitsuryô de 701 e o yôrố ritsuryô que foi reunido em 718 e entrou em vigor em 757 . Veja MARUTSCHKE, Einfubrung in das japanische Rebt, München 1999, pp. 2 ss.

"Maki - Fujiwara, Nibon bóseibi, Tokyo 1993, pp. 32 ss.; Oda, Japanese Lan, 2." ed., London/Dublin/ Edinburgh 1999, pp. 12 ss.

Otake - Maki, op. cit. (1), pp. 54 ss., 81 ss.

${ }^{8}$ Matutschke, op. cit. (4), p. 23. 


\section{b) O período feudal}

O nosso feudalismo começou em 1192 e durou até 1868 . Esse sistema político foi fundado no shôgun, o chefe militar. Ainda que o shôgun devesse ser formalmente nomeado pelo imperador, o imperador não tinha praticamente mais nenhum poder político. A relação feudal baseava-se sobre o serviço dos vassalos ("samurai") e sobre a recompensa dos senhores, através da concessão da posse dos feudos, da carica (carga/função) pública e do domínio sobre campo de arroz, sobre os quais vinham as cobranças dos impostos. Muitos estudiosos definem essa relação como "benevolente" e "moral", em vez de "contratual" como na Europa e evidenciam como os feudatários não fossem obrigados a uma contraprestação em direção aos vassalos".

Na primeita metade do periodo feudal (era de kamakura e de muromacht) desenvolvemse os costumes que faziam frente às exigências do sistema feudal e derrogavam o regulamento do ritsury $\hat{o}$, emanado do imperador e sustentado pela aristocracia. Durante o regime feudal da kamakura, em 1231, foi formado por iniciativa do shôgun um código com 51 artigos (goseibai shikimoku), recolhendo os costumes dos samurai es precedentes judiciátios. Nesse código foi destacada a exigência de julgar conforme a "razão", isto é, o costume dos samurai anotados, precedendo as leis escritas ${ }^{10}$. Todavia, o sbôgun e, depois da sua perda de poder a partir da segunda metade do século XV, os feudatários particulares independentes promulgarão as leis que disciplinavam a relação entre o senhor e os vassalos, a aquisição dos feudos, as rela ções familiares dos vassalos, etc. Essas leis, porém, não foram sistemáticas como ritsuryô, mas só específicas e parciais, de modo que a maior parte do "direito" existia sob forma de cosrume $^{1:}$. A importância dos costumes continuou na segunda metade do período feudal, a era do edo (1603-), mesmo se o shôgun dessa época tenha promulgado algumas leis importantes (por exemplo, buke shohatto e kinchû kuge-shohatto em 1615; kxjikata-osadamegaki em 1742, que foi redigido com base em atenta análise das leis e dos precedentes judiciais, mormente em matéria penal ${ }^{12}$ ) $e$ as associações particulares como as prefeituras, as cidades, os templos, os gilde tinham certas regras próptias.

"Murakami, Hô no rekishi, Tokyo 1997, pp. 16 ss. Alguns estudiosos, ao contrário, destacam o elemento "contratual" ou "sinalagmático" dessa relação feudal. Veja Ôtake -.. Maki, op. oit. (1), p. 112.

${ }^{10}$ Maki - Fujiwara, op. cit. (5), pp. 126 ss. O litulo do domínio sobre os feudos se chamava "cbigyô". Com base no "thigyo" os feudatários podiam fazer valer o ius excludenti; eram previstos, também, o usucapião e a prescrição. Na doutrina japonesa encontram-se ainda hoje diversas opiniōes sobre os caráteres do "chigyô"; alguns o caracterizam como o "Getuere" alemão da Idade Média, que não foi separado do conceito de propriedade, enquanto outros o concebem corno a "possessio" do direito romano. Otake - Maki, op. cit. (1), pp. 130 ss. As causas sobre "cbigyô" tiveram uma tal impottância que fol fundado un processo especial. $O$ processo penal se baseava na inquisição. As leis penais tiveram a finalidade de manter a ordem feudal e a segurança social em vez de disciplinat os crimes e as penas para eliminar a repressão penal arbitrária como o ritst. Ôtake - Maki, op. cit. (1), pp. 149 ss.

${ }^{13}$ Òtake/Maki, op. cit. (1), pp. 154 ss.

${ }^{12}$ Os processos penais se baseavam, ainda, na inquisição. ÔTAKE - MAKI, op. ciit. (1), pp. 232 ss. 
Durante todo o período feudal, a influência da China não foi muito decisiva, mas a parte principal do ordenamento jurídico japonês permanece sempre o diteito penal e administrativo como no ritsuryô. Na era do edo desenvolviam-se também as causas privadas, principalmente sobre os mútuos. Mas o governo era do parecer que as controvérsias pecuniárias deveriam ser resolvidas entre os particulares sem disturbar os tribunais, que foram nessa época ainda os órgãos administrativos do governo: tanto é verdade que o próprio governo promulgou por onze vezes em duzentos anos uma medida segundo a qual aos cidadãos particulares não era permitido ajuizar causa (??) sobre mútuos (aitai-sumashi rei) ${ }^{13}$. Desse modo, desenvolveram-se, por força, meios alternativos, como a conciliação ou a arbitragem, para resolver os conflitos entre os particulares.

\section{c) A recepção do direito ocidental}

No final da era de $e d o$, em 1853 , quatro navios americanos chegaram de surpresa no Japão. Certamente, já havia bastante ocidentais no Japão antes daquela época: os primeiros foram portugueses, que chegaram em 1543 e transmitiram a técnica da espingarda; após, em 1549, chegaram os missionários jesuútas para evangelizar os japoneses no âmbito da Contrareforma. Porém, a partir de 1633, o regime feudal do edo rejeitou o contato com os Estados estrangeiros - com exceção da China e dos Países Baixos - por medo de uma invasão, até 1853 , quando chegaram os americanos. O Japão cedeu ao pedido dos americanos de abrir os portos e concluiu "tratados não paritários" em 1858 com os Estados Unidos, e após como Reino Unido, a Rússia, a França e os Países Baixos. Segundo essas convenções, o Japão devia admitir a jurisdição extraterritorial do consul e renunciar ao direito exclusivo de fixar os impostos. Após a revolução de meiji em 1868 , através da qual o imperador retomou nas mãos o poder político, o governo japonês esforçou-se para áb-rogar os tratados não paritários. Para atingir essa meta, era necessário "modernizar" completamente o sistema jurídico, de modo que os Estados estrangeiros, negociando com os japoneses, estivessem seguros que os litígios entre os particulares fossem julgados num tribunal moderno, por um juiz que aplicasse normas jurídicas certas e sistemáticas ${ }^{14}$. Assim, começou-se a recepcionar, com pressa, o sistema jurídico ocidental, foram convidados professores de direito ou da França ou da Alemanha e foram mandados alguns juristas japoneses ao exterior.

O código penal de 1880 foi redigido por Boissonade, um professor francês que se fixou no Japão entre 1873 e 1895 , com base no direito francês e considerando a doutrina alemã; o artigo 2 declarava a "legalidade das penas", isto é, o princípio enunciado no artigo 8 da "Déclaration des droits de l"bomme et du citoyen" de 1789, e abolia, fundando-se na igualdade dos indivíduos, quase todas as distinções dos crimes segundo o status social do réu. $O$ código penal foi reformado em 1907, com a introdução, sob a influência da doutrina alemã, dos conceitos do subjetivismo e do finalismo das penas; esse código está, com algumas

${ }^{13}$ OKI, Nibonjin no bôkannen, Tokyo, 1983, pp. 158 ss. (principalmente pp. $188 \mathrm{ss.}$ ).

${ }^{14}$ HOSHINO, Mintố no susume. Tokyo, 1998, p. 194. 
modificações, ainda hoje em vigor ${ }^{15}$. O código de processo penal de 1880 , que continha ainda elementos processuais inquisidores, foi preparado por Boissonade e entrou em vigor em 1882 . Foí, porém, reformado já em 1890 , em conformidade com a lei sobre ordenamento judiciário de 1890, que tomou como modelo a lei alemã; também o código de processo civil de 1890 foi recebido da Alemanha ${ }^{16}$. Essa orientação a favor do direito alemão foi reforçada com a promulgação da Constituição japonesa de 1889, que se baseava substancialmente na Constituição alemã.

A Constituição japonesa tomou aquela alemã como modelo porque a forma de Estado alemã, na qual o imperador (Kaiser) tinha fortes poderes com relação ao parlamento, parecia ajustada ao império japonês ${ }^{17}$. Segundo a Constituição japonesa, promulgada pelo próprio imperador, toda a soberania era concentrada em suas mãos, mesmo se fossem fundados diversos órgãos modernos do Estado ${ }^{18}$. $O$ "governo" exa colocado sob o controle do Conselho da Coroa (shthitsw-in) e os poderes do parlamento eram limitados seja sob o ponto de vista da legislação (a aprovação do governo era necessária), seja sob o ponto de vista da redação e do reconhecimento do otçamento (a aprovação do governo era necessária). Também a autoridade de comando supremo das forças armadas pertencia ao imperador; por isso discutiu-se depois da segunda guerra mundial se o imperador era responsável pelo conflito ${ }^{\text {i: }}$.

No que concetne ao código civil japonês, os artigos com relações patrimoniais foram redigidos por Boissonade, segundo o modelo de código civil francês e o resto, sobretudo a parte sobre as pessoas e sobre a familia, foi preparada por "funcionários" japoneses; o código civil foi promulgado em 1890 e a entrada em vigor foi prevista para 1893 (kyth-minpồ). Um grupo de juristas, porém, se opuseram a essa lei, sustentando que tinha sido redigida com pressa, sem levar em consideração a legislação dos outros Estados modernos e que se baseava de modo oportuno no liberalismo e na igualdade dos individuos, destruindo assim a ordem econômica japoneșa constituída sobre a produção coletiva. Esses juristas afirmavam ainda que a parte sobre as pessoas e sobre a família se baseava no individualismo e não correspondia à tradição japonesa. Essa disputa sobre a codificação (Kodifikationsstroit) refletia na realidade a disputa entre os juristas da escola francesa e os da escola inglesa no Japão, isto é, entre os naturalistas e os historicistas. No fim, em 1892, o parlamento decidiu adiar a entrada em vigot do código civil, junto com a do código comercial de 1890 elaborado por um professor alemão, Roesler ${ }^{20}$, e sob o pretexto de modificá-lo foi redigido "por Nobushige Hozumi, Masaaki Tomii e Kenjî́̂ Ume) um projeto inteiramente novo ${ }^{2 !}$.

15 OTAKE - MAKI, op. cit. (1), pp. 280 ss.

${ }^{16} \mathrm{O}$ código do ordenamento judiciário e o código de processo civil foram obra de Techow e de Rudorff, com base no Gerichisverfassungsgesetz e no Zivilprozeßfordmung. Veja MARUTSCHKE, op. sit. (4), P. 37.

${ }^{37}$ Hirofumi Ito, que conduzju pesçuisas sobre constituições de vános países europeus para preparar a codificação, estudou com Rudolf von Grieist em Berlim e com Lorenz von Stein em Viena e propôs a recepção da conscituição

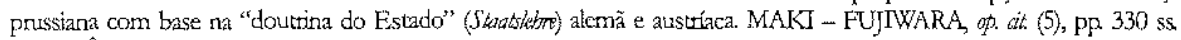

18 OTAKE - MAKI, op. cit. (1), pp. 286 ss.

19 IGARASHI, Einfuhbrung in das japanische Recbt, Darmstadt 1990, pp. 18 ss.

${ }^{20} \mathrm{O}$ código comercial foi promulgado em 1890 e a sua entrada em vigor foi prevista para 1891. OTAKE - MAKI, op. cit. (1), pp. 291 ss.

${ }^{21}$ MAKI - FUJWWARA, op. cit. (5), PP. 351 ss. 
O sistema escolhido não foi mais aquele das institutiones do código civil de 1890 , mas aquele pandetístico (?), próprio do código civil saxão e sucessivamente também do código civil alemão de 1896 (BGB). O sistema pandetístico (3), que previa uma subdivisão em cinco livros (parte geral, das obrigações, dos bens, da família e das sucessões), tinha o mérito de colocar as normas sobre as pessoas no livro I, separado das regras sobre a familia; o "sistema da família", de fato, que refletia os costumes japoneses, foi colocado no início do livro IV, e não no capítulo 13 do livro das pessoas e da familia, como no código civil de 1890 . Desse modo, os primeiros três livros recepcionavam as instituições jurídicas européias modernas, enquanro os livros sobre a família e sobre sucessões refletiam a tradição japonesa ${ }^{22}$. Aprovado pelo parlamento em 1896 (a parte sobre relações patrimoniais) e em 1898 (a parte sobre familia e sucessões), o código civil japonês entrou em vigor em 16 de julho de $1898^{23}$.

A parte sobre as relações patrimoniais, que ainda está em vigor, levava em consideração não apenas os projetos do $B G B$, mas também as legislações de quase trinta países e a jurisprudência da Inglaterra e dos Estados $U_{n i d o s}{ }^{24}$. Porém, na realidade, quase a metade das normas sobre relações patrimoniais do projeto permanecia baseada no código civil francês, como o projeto preliminar de Boissonade. Esse fato se vê hoje sobretudo no direito das coisas, nós não temos o princípio da abstração (Abstraktionsprinzip), mas o principio consensualístico (Konsensualprinzip); temos institutos que não existem no BGB como os privilégios (Vorzugrerbł) e a ação sub-rogatória (Gläubigersurrogation). Não obstante, como muitos estudiosos indicam, praticamente recepcionamos grande parte da doutrina do direito alemão através dos processos de interpretação e de aplicação das normas. Por exemplo, a "culpa in contrabendo" foi introduzida no Japão seguindo a doutrina de Jhering. No que concerne, após, ao inadimplemento das obrigações, ainda que essas regras fossem baseadas no modelo francês, a doutrina e a jurisprudência japonesas introduziram num primeiro momento os três tipos de inadimplemento das obrigações do direito alemão, isto é, mora (Verzug), impossibilidade (Unmöglichkeit) e adimplemento insuficiente (Schlecbterfülung), também conhecido como violação positiva do contrato (Positive Vertragsverletzung). A doutrina

${ }^{22}$ Veja SUZUKI, Die Encwicklung des japanischent Fanilienrechts unter dem Einfluß des europäisches Rechls, em ZugrRiWiss 59 (1957), pp. 184 ss.

${ }^{23}$ MAKI - FUJIWARA, op. cit. (5), pp. 356 ss. Ëmbora a entrada em vigor do código cometcial de 1890 tivesse sido adiada até o tim de 1896, a parte sobre as sociedades, sobre as cambinis e sobre o cheque, assim como a sobre falência entraram em vigor em 10 de julho de 1893 sob requerimento da indústria, sobretudo das câmaras comerciais. Os trabalhos legislativos pelo novo código comercial começaram em 1893, junto àqueles pelo código civil; porém, como o exame dos projetos não avançava por causa da situação política instável, também as partes remanescentes do código comercial de 1890 entraram cm vigor em 1898. O novo código comercial elaborado nesse período foi promulgado $\mathrm{em} 09$ de março de 1899 e entroin em vigor em 16 de junho do mesmo ano. MAKI - FUJIKAWA, op. cit. (5), pp. 369 ss.

${ }^{24}$ HOSHINO, op. cit. (13), pp. $208 \mathrm{ss}$. 
e a jurisprudência japonesas afastaram-se, porém, dessa classificação de proveniência alemã e falam de inadimplemteno tout count ${ }^{25}$.

A parte sobre familia e sucessões, que permaneceu em vigor até 1947, baseava-se no "sistema da família" japonês, is to é, o sistema de "ie" ("casa" no sentido abstrato) ${ }^{26}$, com exclusão da influência das legislações estrangeiras que se orientavam para o individualismo e o libetalismo. Segundo esse sistema da família, o chefe da casa ( $k o s h u$ ), normalmente o pai, representava exteriormente a suá casa constituída por diversas gerações e tinha no interior da casa o poder de decidir os assuntos familiares. A posição do koshu competia por via sucessótia - após a sua morte ou com a retirada da vida ativa (aposentadoria?) - ao primogênito, com o seu patrimônio pessoal e o da casa (katoku-sôzoku); na otdem sucessória, o filho homem, natural ou adotado, precedia a filha mulher ${ }^{27}$. O registro do estado das pessoas era ordenado com base no chefe da casa e os membros da casa eram registrados conforme a relação com ele. O matrimônio significava unir duas casas e ocorria, por isso, o consenso do kash $u^{28}$. O divórcio acontecia quase sempre (em 1940, 99,2\% dos divórcios) "consensualmente", em vez de judicialmente: divórcio "consensual" significava, nesse período, de fato, "repudiar a esposa", afastando-a da casa na qual era casada ${ }^{29}$. O fim de respeitar a ordem familiar correspondia à ideologia do governo de meiji, que pretendia sustentar o Estado como uma familia, em cujo topo se encontrava o imperador. O governo reintroduziu o pensamento do shintoismo, a religião japonesa, e a ideologia do confucionismo para fazer respeitar a hierarquia na família e na sociedade ${ }^{30}$.

De qualquer modo, com esse processo de codificação o Japão fundou um ordenamento jurídico completo e conseguiu, portanto, ab-rogar os tratados não paritários estipulados com os Estados ocidentais. O Japão sentia-se, pouco a pouco, orgulhosamente, como um dos Estados mais fortes do mundo, enquanto não perdesse a segunda guerra mundial.

${ }^{25}$ Veja KITAGAWA, Das Methodemproblem in der Dogmatik des japanischen und bürgertichen Rechts, in AcP 166 (1966), pp. 330 ss.; ID., Drei Enhvicklungsphasen im japanischen Zivilrecbt, in Die Japanisierung des westlichen Rechts. Japanisch-deutsches Symposion in Tübingert vom 26. bis 28. Juli 1988, A CURA DI H. COING, HIRANO, KITAGAWA, etc., Tübingen 1988, pp. 125 ss. O artigo 415 do código civil japonés dispõe: "Leistet der Schuldner nicht dem Inbalt der Schsild entsprecbend, so kann der Gläubiger Schadensersatz verlangen. Dasselbe gilt, wenn die Leistung in Folge eines vom Schuldner z" vertretenten Umstandes unmogglich geworden ist". Veja MLARUTSCHKE, op. ait. (4), pp. 156 ss. O artigo $415 \$ 1$ do código civil japonês corresponde ao artigo 1218 do código civil italiano de 1942 .

${ }^{26}$ SUZUKI afirma que o conceito de "ie" correspondia àquele de "gens", em vez daquele de "familia" no direito romano. SUZUKI, op. cit. (21), p. 186.

27 TANIGUCHI, Über das beutige japanische 'Fantilien-System', in RatbelsZ 10 (1936), pp. $484 \mathrm{ss}$.

${ }^{28}$ É de se notar que também um matrimônio contraído sem o consenso do konshu era válido, se fosse inscrito no cadastro de familia; o koshu, porém, poderia excluir quem havia contraído o matrimônio sem o seu consenso da casa e the tolher o direito de sucessão. TANIGUCHI, op. cit. (26), p. 480.

${ }^{20}$ MIZUNO, Grounds for Divore in Japanese Law and Mecbanisms of Divore Payment Obligation, in Japanese Reports for the XIV th Intermational Congress of Comparative I aw (Athens, July 31" - August 6" 1994), Tóquio 1995, pp. 89 ss.

${ }^{30}$ Cfr. SUZUKI, op. cit. (21), pp. 186 ss. É de se notar que a tnaior parte da população no período de edo era formada por camponeses, que tinham cosiumes diversos daqueles dos samurai. Por isso, o sistema da familia que foi disciplinado no código civil de 1898 não cortespondia sempre à realidade e às exigências da sociedade inteira. Ibidem, pP. 194 ss.; veja também SUZUKI, Die Modemisientng des jataniscben Families - and Erbrechts, in RabelsZ 19 (1954), pp. 116 ss. 


\section{d) Depois da segunda guerra mundial}

Após a segunda guerra mundial, os Estados Unidos ocuparam o Japão e democratizaram e liberalizaram o nosso sistema social e econômico: por exemplo, foram liberados os consórcios monopolistas e foram divididos os bens imóveis dos grandes proprietários (latifundiários). Na reforma da Constituição japonesa, a primeira questão foi essa: mantemos o imperador ou não? Os americanos pensavam que o imperador tivesse sido tesponsável pela segunda guerra mundial e, portanto, essa figura devia ser eliminada. Entretanto, como não queriam destruir completamente a sociedade japonesa e tinham interesse em ser partner do Japão, que se situava numa posição estratégica do ponto de vista militar, ou seja, perto da Coréia e da China, no fim, consentiram em manter o imperador. Na nossa constituição, vigente desde 1947, o imperador tem o papel de "símbolo do Japão e da nação japonesa" "3it.

No campo do direito civil, o direito de familia foi completamente modificado; o sistema da familia patriarcal foi ab-rogado e o matrimônio foi considerado pela primeira vez como una comunidade do homem e da mulher, tendo como base a paridade entre os $\operatorname{sexos}^{32}$. No direito comercial e econômico, a influência do direito americano foi marcada: por exemplo, o sistema do conselho de administração e do conselho fiscal (de vigilância?) da sociedade por ações seguiu o modelo dos Estados Unidos ${ }^{33}$. No conjunto, de qualquer modo, o ordenamento jurídico japonês continuava a ser orientado ao sistema romanogermânico, como antcriormente ${ }^{34}$.

\section{As características do ordenamento juridico japonês}

Observando o ordenamento jurídico japonês, muitos estudiosos europeus, principalmente os comparatistas, como René David ${ }^{35}$, Zweigert e $\mathrm{Kötz}^{36}$, Sacco ${ }^{37}$, etc.,

\footnotetext{
31 A constituç̧̃o foi promulgada en 03 de novembro de 1946 e entrou em vigor em 03 de maio de 1947.

32 Veja SUZUKI, op. cit. (29), pp. 110 ss. A lei de reforma foi promulgada em 22 de dezembro de 1947 e entrou em vigor em $1^{\circ}$ de janciro de 1948.

${ }^{33} \mathrm{MAKI}$ - FUJIWARA, op. cit. (5), p. 456.

34 ODA, op. cit. (5), pp. 29 ss.

${ }^{35}$ RENÉ DAVDD admite que existem grandes diferenças entre os Estados asiáticos como a China, o Japão, a Mongólia, a Coréia e os Estados da Indochina, mas afirma também que é possível encontrar certas características comuns entre esses paises, como por exemplo a funçäo subsidiária do direito, a tendência de evitar os conflitos e a conservação da ordexs social com instrumentos de conciliação e mediação. R. DAVID - C. JAUFFRET-SPINOSI, I grandi sistemi gitaridici contemporanei, traduzido da $10^{2}$ ediçăo (1992) por O. CALLIANO.. [et al.] sob a direção de R. SACCO, Padova 1994, pp. 450 ss.

${ }^{36}$ ZWEIGERT E KÖTZ sustentavam até a segunda edição de seu livro "Introduzzione al dirito comparato" a opinião segundo a qual o direito chinês e o japonês ANDAVANO classificados no sistema jurídico (Recbtskereis) do Extremo Oriente. K. ZWEIGERT - H. KOTZ, Introduzione al diritto comparato, edição italiana organizada por A. DI MAJO e A. GAMBARO, vol. 1, Principi fondamentath, tradução de B. POZZO, Milão, 1992, pp. $359 \mathrm{ss}$.

${ }^{37}$ Também SACCO fala do "direito do Extremo Oreinte" no qual são incluidos a China e o Japào. GAMBARO - SACCO, op. cit. (1), Pp. 505 ss.
} 
acentuaram até hoje a função subsidiária do direito, isto é, a tendência de evitar os conflitos e a conservar a ordem social com instrumentos de conciliação e mediação e classificaram o sistema japonês junto ao chinês, coreano, etc. no "grupo do Extremo Oriente". Segundo a minha opinião, o ordenamento jurídico da China e o do Japão são muito diversos; a influência chinesa sobre o direito japonês limitou-se ao tempo antigo e, em particular, após a recepção dos códigos europeus no Japão, na Idade Moderna, não podemos identificat o nosso ordenamento jurídico com o chinês ${ }^{38}$.

Todavia, isso não significa que o nosso ordenamento jurídico tenha se tornado completamente europeu, pelo contrátio, permanecem certas características japonesas na atuação do direito. Muitos dentre os mesmos estudiosos japoneses chamam novamente a atenção sobre a subdesenvolvida "consciência juridica" (Rechtshenufistsein) dos japoneses. Kawashima escrevia, em 1967, que a sociedade japonesa ainda era subdesenvolvida e pré-moderna, que os japoneses não estavam em condições de decidir entre branco e preto e não faziam valet os seus direitos subjetivos. Por esse motivo, ainda havia uma ruptura entre "as leis recepcionadas da Europa" e "a consciência jurídica na sociedade japonesa". Somente com o passar do tempo os japoneses seriam tornados conscientes do direito e seriam aproximados da sociedade ocidental ${ }^{39}$.

A essa tese se opõe $O k i$, sustentando que a consciência jurídica dos japoneses era suficientemente desenvolvida já no periodo do edo porque havia muitas causas privadas; somente devido à falta de um sistema judiciário, os japoneses eram habituados a resolver os conflitos entre eles, por via extrajudicial ${ }^{40}$. Murakami faz notar, porém, que na era de edo não era desenvolvida entre os governantes a idéia de garantir a tutela jurisdicional aos cidadãos para que fossem garantidos os seus direitos; nem também era imaginável pata os cidadãos exigir do governo que os seus casos fossem examinados num processo justo. $\mathrm{Na}$ Europa o estado de conflito era a situação normal e devia-se sempre procurar resolver as controvérsias julgando-as conforme a alternativa da "justiça" e da "injustiça", para defender o próprio direiro contra os outros. No Japão, ao contrário, a harmonia e a paz eram o estado normal, por isso o governo feudal paternalista protegia os nembros da sociedade. Não erá possível para nós desenvolver nos "cidadãos" uma consciência do tipo ocidental, isto é, que fossem

34 Veja OKI, Hikakuhò kôgi, Tóquio 1992, pp. 117 ss.; MARUTSCHKE, op. cit. (4), p. 5; BAUM, Rechtsdenezn, Rechtisystem und Recblswirkfichleeit in Japan - Rechtsveryleichung mit Japan-, in RabelsZ 59 (1995), pP. $259 \mathrm{ss} . \mathrm{Na} 3^{a}$ edição da obra de ZWEIGERT e KÖTZ, organizada por KÖTZ e publicado em 1996, não aparece ("SAl??") mais a classificação do sistema juxidico do Extremo Oriente; mas o direito japonês a o direito chinès constituem ainda um único capitulo ("Recht im fernefl Osten") e KÖZ segue mâs ou menos ainda a leitura tradicional, destacando a influência do confucionismo sobre a sociedade japonesa. K. ZWEIGERT - H. KÖTZ, Einfubrung in die Rechtsvergleichsung, 3a ed., Tübingen 1996, pP. 280 ss.

39. KAWASHIMA, Nibonjin no böishiki, Tóquio 1967, pp. 5 ss.

${ }^{40}$ OKL, op. ait. (12), pp. $201 \mathrm{ss}$. 
cientes de sustentar a sociedade, e também de poder exaltar os direitos quando necessário. Esse fenômeno japonês reflete segundo Murakami, ainda hoje, a consciência jurídica subdesenvolvida dos japoneses ${ }^{41}$.

A diferença que na Europa continental, onde o fundamento do sistema jurídico foi o direito romano, que se baseava nas normas privadas, no Japão o direito era antes de tudo fundado sobre o direito público, ou seja, sobre direito administrativo e penal. Aqui, o direito "emanado da autoridade" funciona em primeiro lugar como norma de decisão (Entscheidungsnorm), que era individualizada e aplicada somente após a emersão dos conflitos, em vez de funcionar como norma de conduta (Handlungsnorm), que garantisse a previsibilidade da solução dos conflitos e, nesse sentido, serve para impedir a insurgência das controvérsias. Por exemplo, numa relação contratual os japoneses não fixarn exatamente o direito e a obrigação das partes antecipadamente, mas preferem deixar espaço para resolver os problemas negociando e encontrando um compromisso; o direito intervém somente quando não é mais possível resolver os conflitos entre as partes ${ }^{42}$.

Após cem anos de experiência, o direito ocidental está colocando as raízes no Japão, tmas num modo específico. Os europeus pasmam-se quando vêem como os juízes japoneses interpretam as normas legais livremente, sobretudo com base no "jorr", que significa "ratio" ou "natureza das coisas" (Natur der Sache), e muito freqüentemente referem-se em seu juizo as cláusulas gerais como bona fides (art. 1 n. 2 do código civil japonês ${ }^{43}$ ) ou buoni costumi (art. 90 do código civil japonês $\left.s^{44}\right)$. Na Europa, os juizes têm a obrigação de garantir a previsibilidade e a estabilidade jurídica, enquanto no Japão os júzes recorrem amplamente à discricionariedade e não hesitam em se distanciar do texto das disposições para chegar ao resultado mais adequado e equilibrado. O direito, como último meio ao qual se dirige para resolver os conflitos, é empregado mais livremente no Japão do que na Europa.

${ }^{41}$ MURAKAMI, op. cit. (8), pp. 11 ss.; Io., Zur Struktur des japanischen Recbts, in ZjapanR 7 (1999), pp. 7 ss. Sobre a consciência juxídica dos japoneses, veja-se a nonografia de RAHN, Rechtsdenken und Rechtsauffassung in Japan. Dargestellt an der Entwicklung der modernen japanistben Zivilrechtsmethodit, München, 1990.

${ }^{42} \mathrm{Na}$ era meiji, após a recepção do sistema jurídico ocidental, havia umá norma no código de processo civil segundo o qual o juiz podia emitir um parecer vinculante para a conciliação. A estaústica nos diz que de 1878 a 1885 , cerca de 80 a $90 \%$ dos litígios nos tribunais de primeiro grau foram resolvidos através da conciliação. MARUTSCHKE, op. cit. (4), pp. 40 ss. Também hoje, a importância da solução dos conflitos pela conciliação é ressaltada.

${ }^{43}$ Veja Art. 242 BGB (Die Erfordernis der Leistung nach Treu und Glauter).

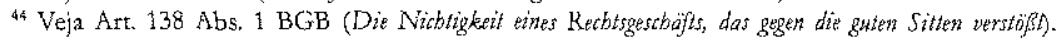

